\title{
Gastric Cancer Presenting as Persistent Pneumonia: An Unusual Case Report
}

\author{
Aretha Kou ${ }^{1}$, Jinal K. Patel ${ }^{1}$, Itioye Adetula ${ }^{1}$, Johnathan Frunzi ${ }^{1}$ \\ 1. Internal Medicine, Medical Center of Trinity, Trinity, USA
}

Corresponding author: Aretha Kou, aretha.kou@hcahealthcare.com

\begin{abstract}
Worldwide, gastric cancer is the fifth most common cancer and the third leading cause of cancer deaths, which carries a poor prognosis as only $28.3 \%$ are expected to survive after five years. The incidence varies depending on the geographical locations and dietary patterns. Here, we present a case of a 59-year-old Hispanic male with a 10-month history of recurrent bilateral pneumonia and dysphagia. Diagnostic workup revealed metastatic gastric adenocarcinoma.
\end{abstract}

Categories: Gastroenterology, Oncology, Pulmonology

Keywords: gastric cancer, smoking, fifth most common cancer, male sex, alcohol use, obesity, helicobacter pylori, dysphagia, abdominal pain, nausea

\section{Introduction}

Worldwide, gastric cancer is the fifth most common cancer and the third leading cause of cancer deaths [13]. Gastric cancer carries a poor prognosis as only $28.3 \%$ are expected to survive after five years [1-5]. The incidence of gastric cancer is less common in North America, Australia, New Zealand, Southern Asia, and North and East Africa [1]. However, there is a higher incidence in Eastern Asia, Central, Eastern Europe, and South America [2]. The higher incidence is attributed to dietary patterns, socioeconomic status, and Heliobacter pylori infections [2]. Despite the highest incidence in Eastern Asia, Central and Eastern Europe, and South America, it is more common among Hispanics, African Americans, and Native Americans when compared to non-Hispanic whites in the United States [2]. Also, gastric cancer is two-three times more common in men than in women [1].

On the other hand, there is a lower incidence of gastric cancer in the United States [2]. Despite the number of new cases declining by $1.5 \%$ annually in the United States for the past 10 years [6], The American Cancer Society estimated 27,600 new cases of gastric cancer in 2020 [6]. Of that, 11,010 people were estimated to die [6]. In the United States, most cases of gastric cancer by the time of diagnosis have progressed to advanced, incurable disease $[1,3,4]$. This further illustrates the need to screen patients with risk factors (smoking, male gender, ethnicity, diet, obesity, Helicobacter pylori [H. Pylori], alcohol, abdominal radiation therapy) $[1-5,7]$. Here, we present a case of a 59-year-old Hispanic male with a 10-month history of recurrent bilateral pneumonia and dysphagia diagnosed as gastric cancer.

Review began 03/09/2021 Review ended 03/17/2021 Published 03/21/2021

\section{() Copyright 2021}

Kou et al. This is an open access article distributed under the terms of the Creative Commons Attribution License CC-BY 4.0., which permits unrestricted use, distribution, and reproduction in any medium, provided the original author and source are credited.

\section{Case Presentation}

A 59-year-old Hispanic male with a past medical history of diabetes, hyperlipidemia, chronic obstructive pulmonary disease (COPD), and remote smoking history (quit 29 years ago) was admitted to the hospital by his pulmonologist for recurrent bilateral pneumonia over the past 10 months. The patient's initial symptom was a cough associated with lying supine, eating, or drinking. He also reported that his oxygen saturation would decrease to the 80 s while sleeping and unintentional weight loss of 40 pounds over the past 10 months. On further questioning, the patient reported having progressive dysphagia from solids to liquid over the past 10 months.

He reported being admitted to a different hospital approximately three-weeks prior, where he was diagnosed with persistent pneumonia and treated with antibiotics and steroids. The patient's hospital course was complicated secondary to pleural effusion, which required a thoracentesis. Pleural fluid analysis was negative for malignancy. CT scan of the chest during his previous hospital stay revealed extensive bilateral infiltrates and a $3 \mathrm{~cm}$ density in the left upper lobe. He was discharged and to follow up as outpatient with his pulmonologist.

On this admission, his initial vital signs were temperature $98.2 \mathrm{~F}$, pulse 84 beats per minute, respiratory rate 15 breaths per minute, blood pressure $111 / 69 \mathrm{mmHg}$, and oxygen saturation $93 \%$ on room air. Physical examination was significant for rhonchi and lymphadenopathy. Chest X-ray and CT of the chest showed pneumonic infiltrates and pleural effusion (Figure 1 and Figure 2, respectively), which required drainage by thoracentesis. 


\section{Cureus}

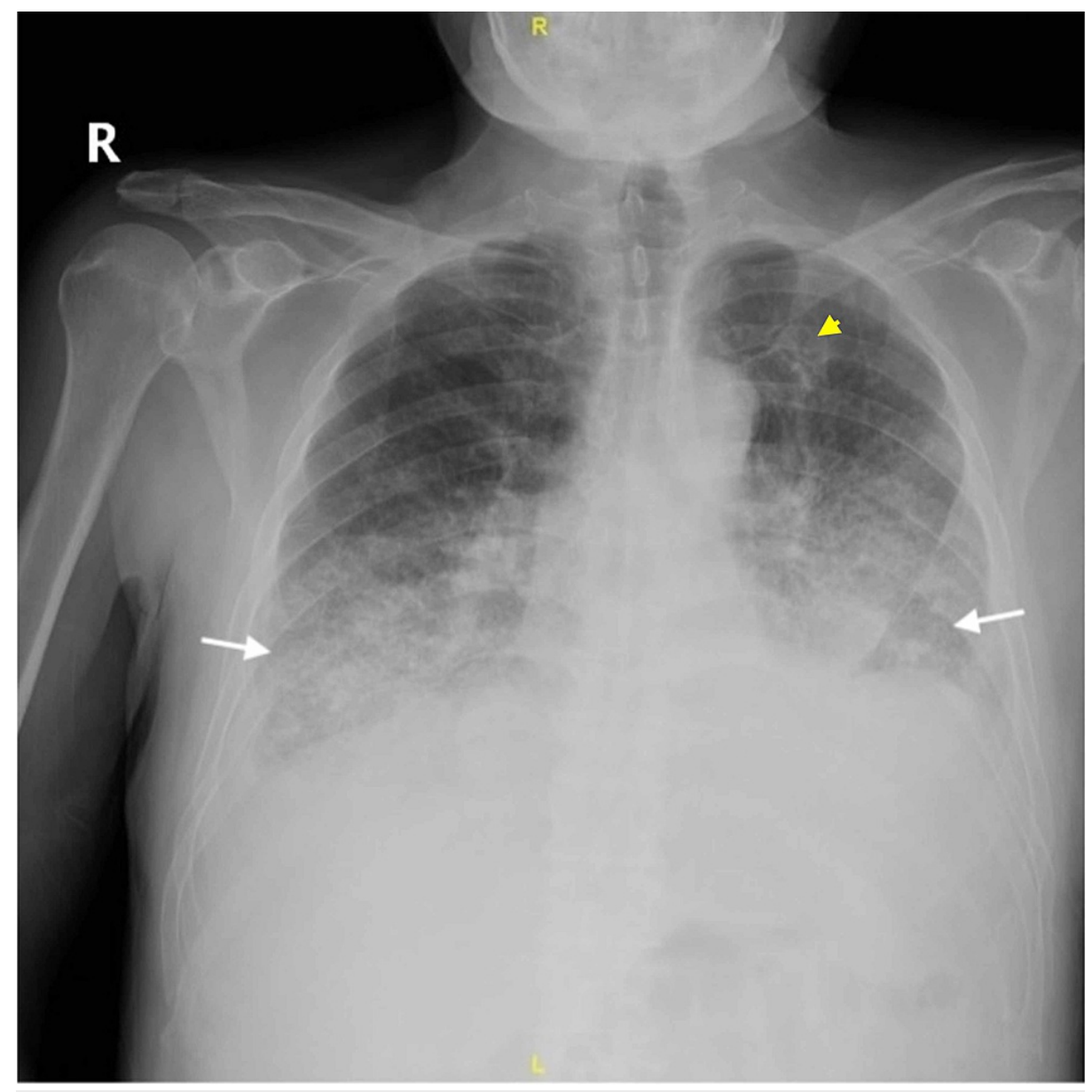

FIGURE 1: Chest X-ray.

Bilateral lower lobe effusion and consolidation (lower arrows), left upper lobe nodule (yellow arrow). 


\section{Cureus}

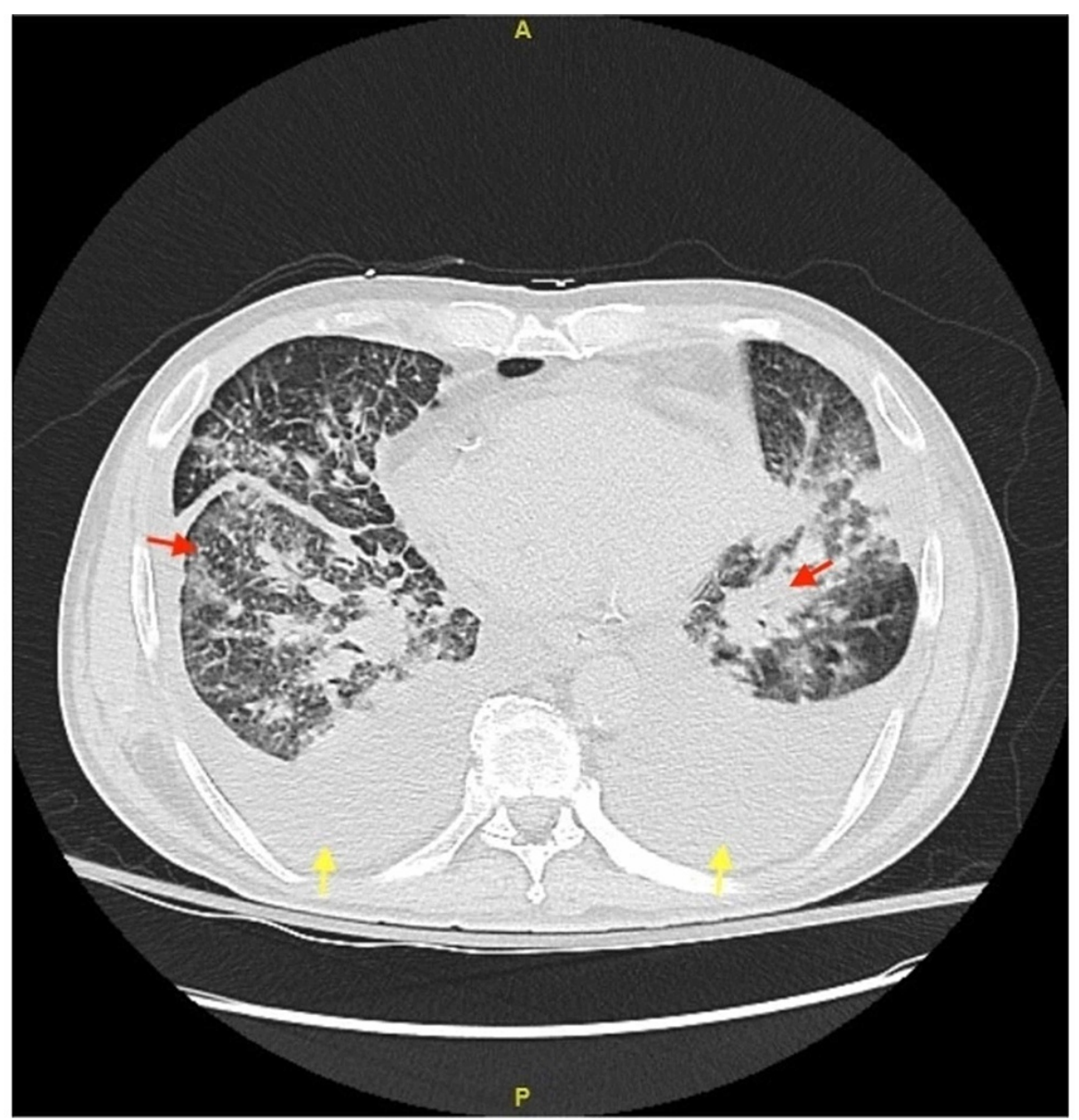

\section{FIGURE 2: Computerized tomography of the chest.}

Bilateral pleural effusions (yellow arrows) with consolidation and possible metastases (red arrows).

As the patient had dysphagia and weight loss, a barium swallow was done, which was remarkable for slow emptying and severe backflow in the esophagus followed by coughing associated with dysphagia. The patient had undergone an esophagogastroduodenoscopy (EGD) due to findings on barium study. EGD revealed a gastric fundi mass approaching the gastroesophageal junction. Biopsies taken from the gastricmass were positive for gastric adenocarcinoma. A repeat thoracentesis was performed. Pleural fluid cytology was positive for gastric adenocarcinoma.

A follow-up CT of the abdomen and pelvis and bone scan revealed metastatic disease (Figure 3 and Figure 4, respectively). Furthermore, the patient required bilateral indwelling pleural catheters secondary to having persistent pleural effusions and a percutaneous endoscopic gastrostomy tube for nutritional support. Oncology had determined that the patient was not a candidate for chemotherapy. Ultimately, the patient was transferred to an inpatient hospice unit as he had a short life expectancy due to having severe metastatic gastric adenocarcinoma. 


\section{Cureus}

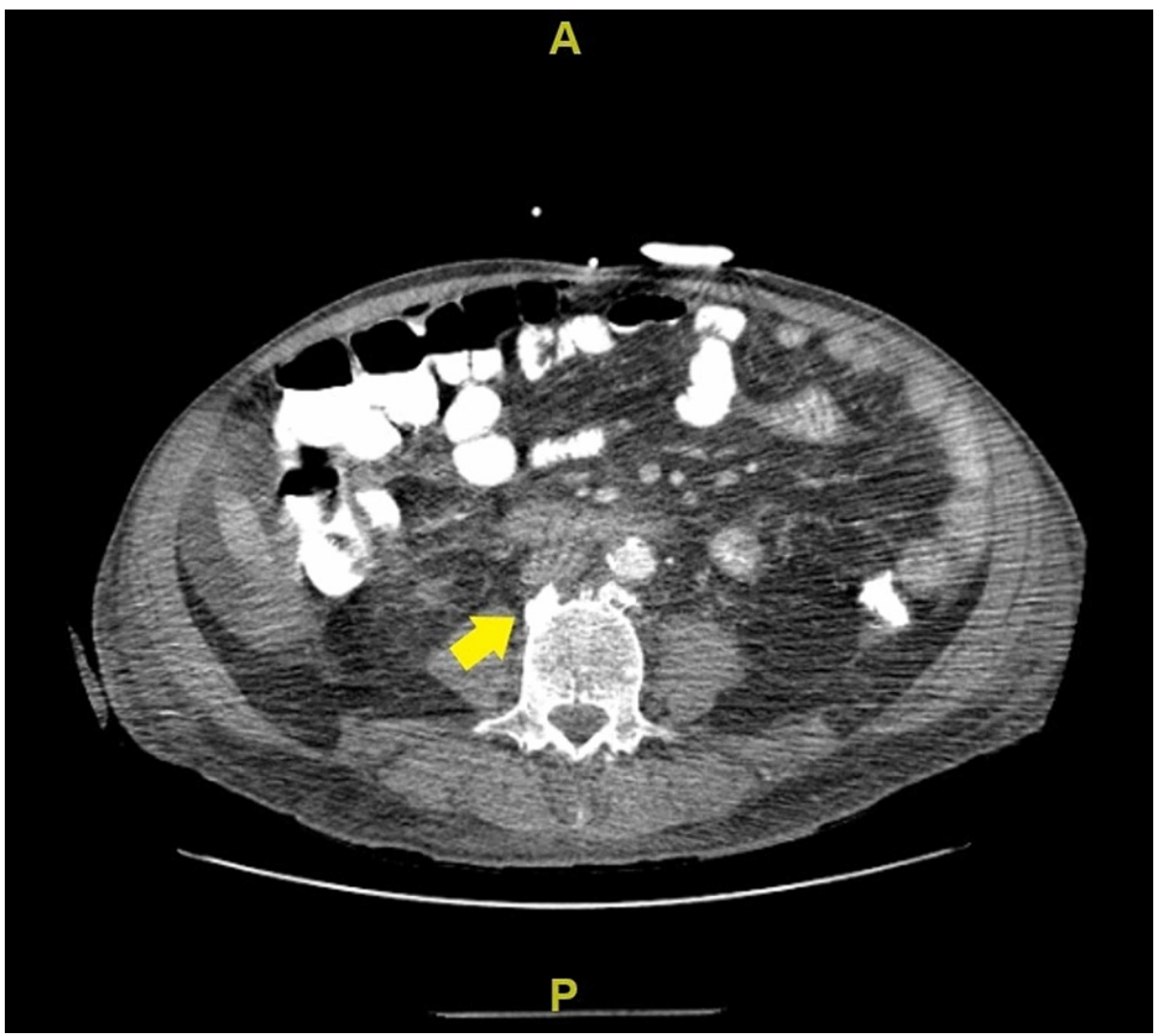

FIGURE 3: Computerized tomography scan of abdomen and pelvis.

Sclerotic lesions in the thoracolumbar spine (yellow arrow) highly suspicious for osseous metastasis.

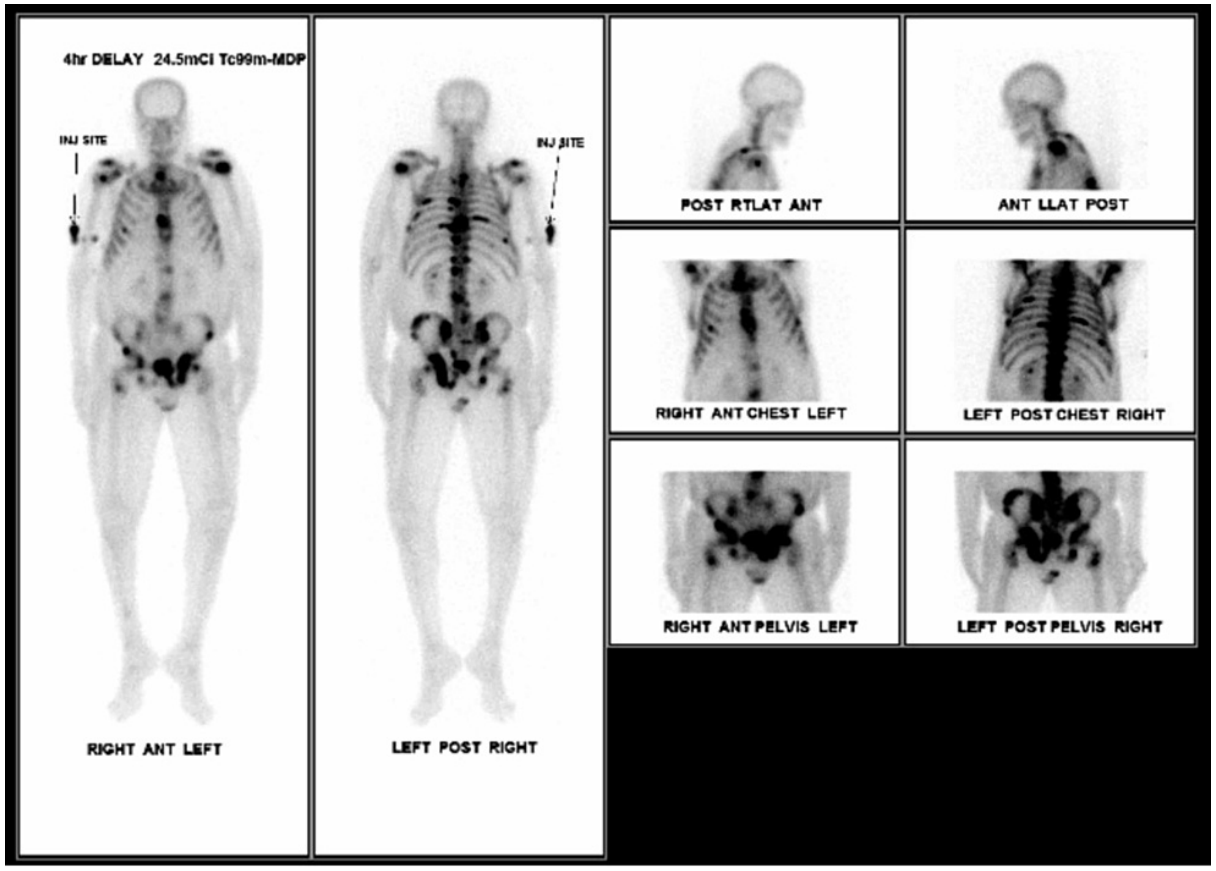

\section{FIGURE 4: Bone scan}

Multiple areas of increased uptake are seen involving the spine, ribs, pelvis and proximal femurs and left proximal humerus consistent with osseous metastatic disease. 


\section{Discussion}

Gastric cancer usually is diagnosed in the 6th decade of life, with an average of 68 years old $[1,3-6]$. However, our patient presented almost a decade earlier, likely due to multiple risk factors (male gender, smoking history, ethnicity, alcohol use). Early signs and symptoms of gastric cancer can be vague, more commonly attributing it to abdominal pain, weight loss, and nausea $[1-4,8,9]$.

Smoking and heavy alcohol consumption increase the risk of gastric cancer by approximately $80 \%[1,7]$. Our patient's risk factors included smoking history, male gender, and ethnicity. On the other hand, a history of H. pylori, a Class I bacterial carcinogen that causes $90 \%$ of all gastric carcinomas, is a risk factor [1-5], which our patient did not have.

The most common sites of metastases include the liver (48\%) and peritoneum (32\%) [10,11]. Less commonly, bone (12\%), lung (15\%), pleura/mediastinum (6\%), or nervous system (3\%) metastases can occur [10,11]. Our patient had cervical and axillary lymphadenopathy suggestive of lymph node metastases. Our patient also had distant metastases to the lung, pleura, and thoracolumbar spine.

Specifically, malignant pleural effusion is most commonly associated with lung cancer (35\%-46\%) and breast cancer (8\%-40\%) [12]. Malignant pleural effusions from gastrointestinal adenocarcinoma has a prevalence of $2 \%$ [12]. Additionally, cytology has a mean sensitivity of $60 \%$ [12,13], which may explain why the patient's initial cytology was negative. Although cytology is an approved initial test, it is dependent on cytologist experience, sample preparation, and primary tumor etiology [12].

Our patient's prognosis remained poor due to having diffuse metastases. Unfortunately, metastatic gastric cancer has a poor prognosis with a five-year survival rate of 5\% [14]. Treatment primarily consists of chemotherapy and palliative care [14]. This case report further illustrates that most cases of gastric cancer by the time of diagnosis have progressed to advanced, incurable disease $[1,3,4]$.

\section{Conclusions}

Although gastric cancer is one of the most common cancers worldwide, gastric cancer is still underdiagnosed in North America. Thorough history taking along with a strong clinical suspicion can improve gastric cancer morbidity and mortality. Also, it is important to coordinate care among multiple specialists as early as possible. These steps are vital to improving patient mortality, as well as quality of life.

\section{Additional Information}

\section{Disclosures}

Human subjects: All authors have confirmed that this study did not involve human participants or tissue. Conflicts of interest: In compliance with the ICMJE uniform disclosure form, all authors declare the following: Payment/services info: All authors have declared that no financial support was received from any organization for the submitted work. Financial relationships: Kou A, Patel JK, Adetula I, Frunzi J declare(s) Disclaimer from HCA Healthcare and/or an HCA Healthcare affiliated entity. This research was supported in part by HCA Healthcare and/or an HCA Healthcare affiliated entity. The views expressed in this publication represent those of the author(s) and do not necessarily represent the official views of HCA Healthcare or any of its affiliated entities. Other relationships: All authors have declared that there are no other relationships or activities that could appear to have influenced the submitted work.

\section{References}

1. Machlowska J, Baj J, Sitarz M, Maciejewski R, Sitarz R: Gastric cancer: epidemiology, risk factors, classification, genomic characteristics and treatment strategies. Int J Mol Sci. 2020, 21:4012. 10.3390/ijms21114012

2. Marqués-Lespier JM, González-Pons M, Cruz-Correa M: Current perspectives on gastric cancer . Gastroenterol Clin North Am. 2016, 45:413-428. 10.1016/j.gtc.2016.04.002

3. Smyth EC, Nilsson M, Grabsch HI, van Grieken NC, Lordick F: Gastric cancer. Lancet. 2020, 396:635-648 10.1016/S0140-6736(20)31288-5

4. Venerito M, Vasapolli R, Rokkas T, Malfertheiner P: Gastric cancer: epidemiology, prevention, and therapy . Helicobacter. 2018, 23:e12518. 10.1111/hel.12518

5. Thrift AP, El-Serag HB: Burden of gastric cancer. Clin Gastroenterol Hepatol. 2020, 18:534-542. 10.1016/j.cgh.2019.07.045

6. Key statistics about stomach cancer. Cancer.org . (Updated January 8, 2020). Accessed: October 2, 2020: https://www.cancer.org/cancer/stomach-cancer/about/key-statistics.html..

7. Moy KA, Fan Y, Wang R, Gao YT, Yu MC, Yuan JM: Alcohol and tobacco use in relation to gastric cancer: a prospective study of men in Shanghai, China. Cancer Epidemiol Biomarkers Prev. 2010, 19: 10.1158/10559965.EPI-10-0362

8. Wanebo HJ, Kennedy BJ, Chmiel J, Steele G, Winchester D, Osteen R: Cancer of the stomach: p patient care study by the American College of Surgeons. Ann Surg. 1993, 218:583-592. 10.1097/00000658-19932185000002

9. Nölting S, Ullrich M, Pietzsch J, et al.: Current management of pheochromocytoma/paraganglioma: a guide 


\section{Cureus}

for the practicing clinician in the era of precision medicine. Cancers. 2019, 11:1505.

10.3390/cancers11101505

10. Riihimäki M, Hemminki A, Sundquist K, Sundquist J, Hemminki K: Metastatic spread in patients with gastric cancer. Oncotarget. 2016, 7:52307-52316. 10.18632/oncotarget.10740

11. Wittekind C: The development of the TNM classification of gastric cancer . Pathol Int. 2015, 65:399-403. 10.1111/pin.12306

12. Skok K, Hladnik G, Grm A, Crnjac A: Malignant pleural effusion and its current management: a review . Medicina. 2019, 55:490. 10.3390/medicina55080490

13. Huang Y, Eltelbany M, Chow RD, Sood A: Peritoneal carcinomatosis, unilateral malignant pleural effusion with bilateral hydronephrosis post-radical gastrectomy in a signet-ring gastric cancer patient: a case report. J Community Hosp Intern Med Perspect. 2020, 10:140-144. 10.1080/20009666.2020.1742511

14. Charalampakis N, Economopoulou P, Kotsantis I, et al.: Medical management of gastric cancer: a 2017 update. Cancer Med. 2018, 7:123-133. 10.1002/cam4.1274 